\title{
High Neonatal Mortality Rates in Rural India: What Options to Explore?
}

\author{
Ravi Prakash Upadhyay, ${ }^{1}$ Palanivel Chinnakali, ${ }^{2}$ Oluwakemi Odukoya, ${ }^{3}$ Kapil Yadav, ${ }^{4}$ \\ Smita Sinha, ${ }^{5}$ S. A. Rizwan, ${ }^{4}$ Shailaja Daral, ${ }^{1}$ Vinoth G. Chellaiyan, ${ }^{1}$ and Vijay Silan ${ }^{4}$ \\ ${ }^{1}$ Department of Community Medicine, Vardhman Mahavir Medical College and Safdarjang Hospital, New Delhi 110049, India \\ ${ }^{2}$ Department of Community Medicine, Indira Gandhi Medical College and Research Institute, Puducherry 605009, India \\ ${ }^{3}$ Department of Community Health and Primary Care, College of Medicine, \\ University of Lagos, Lagos 23401, Nigeria \\ ${ }^{4}$ Centre for Community Medicine, All India Institute of Medical Sciences, New Delhi 110029, India \\ ${ }^{5}$ School of Public Health, Postgraduate Institute of Medical Education \& Research (PGIMER), Chandigarh 160012, India
}

Correspondence should be addressed to Ravi Prakash Upadhyay, ravi.p.upadhyay@gmail.com

Received 13 August 2012; Accepted 16 September 2012

Academic Editors: M. Adhikari, G. J. Casimir, and R. G. Faix

Copyright (c) 2012 Ravi Prakash Upadhyay et al. This is an open access article distributed under the Creative Commons Attribution License, which permits unrestricted use, distribution, and reproduction in any medium, provided the original work is properly cited.

\begin{abstract}
The neonatal mortality rate in India is amongst the highest in the world and skewed towards rural areas. Nonavailability of trained manpower along with poor healthcare infrastructure is one of the major hurdles in ensuring quality neonatal care. We reviewed case studies and relevant literature from low and middle income countries and documented alternative strategies that have proved to be favourable in improving neonatal health. The authors reiterate the fact that recruiting and retaining trained manpower in rural areas by all means is essential to improve the quality of neonatal care services. Besides this, other strategies such as training of local rural healthcare providers and traditional midwives, promoting home-based newborn care, and creating community awareness and mobilization also hold enough potential to influence the neonatal health positively and efforts should be made to implement them on a larger scale. More research is demanded for innovations such as " $m$-health" and public-private partnerships as they have been shown to offer potential in terms of improving the standards of care. The above proposed strategy is likely to reduce morbidity among neonatal survivors as well.
\end{abstract}

\section{The Scale of the Problem of Neonatal Deaths in India}

Globally four million deaths occur every year in the first month of life [1]. Almost all (99\%) neonatal deaths arise in low-income and middle-income countries $[1,2]$. In India alone, around one million babies die each year before they complete their first month of life, contributing to one-fourth of the global burden $[1,3]$. The neonatal mortality rate in India was 32 per 1000 live births in the year 2010, a high rate that has not declined much in the last decade $[4,5]$. India's neonatal mortality rate dropped significantly, that is, by $25 \%$, from 69 per 1,000 live births in 1980 to 53 per 1,000 live births in 1990 followed by a $15 \%$, decline from 51 to 44 per 1,000 live births between 1991 and 2000. In recent years the NMR has dropped by $15 \%$ that is, from 40 per 1000 live births in 2001 to 34 per 1000 live births in 2009 [4]. Urban-rural differences in neonatal mortality exist with the mortality rates higher by $50 \%$ in rural $(42.5 / 1000$ live births) compared to urban (28.5/1000 live births) areas, as per the National Family Health Survey (NFHS-3) [6]. The common causes of neonatal deaths in India include infections, birth asphyxia, and prematurity which contribute to $32.8 \%, 22.3 \%$, and $16.8 \%$ of the total neonatal deaths, respectively $[7,8]$.

India is one of the ten countries, along with China, Democratic Republic of Congo, Pakistan, Nigeria, Bangladesh, Ethiopia, Indonesia, Afghanistan, and Tanzania, that account for more than $65 \%$ of all intrapartum related neonatal deaths [9]. Despite the recognition of neonatal survival as 
a key to child survival, poor progress in neonatal survival in India poses concern regarding attainment of the fourth Millennium Development Goal (MDG) target, that is, to reduce under- 5 child mortality by two-thirds by 2015 .

\section{Healthcare Scenario in Rural India}

2.1. Rural Health Infrastructure. Despite having a comparatively higher neonatal mortality rate, rural India is tackling with the problem of ill equipped public health facilities. The numbers of existing peripheral health facilities fall short of what has been recommended by the government of India. The healthcare in rural areas has been developed as a threetier structure based on predetermined population norms. The subcenter is the most peripheral institution and the first contact point between the primary healthcare system and the community. Primary Health Centers (PHCs) comprise the second tier in rural healthcare structure envisaged to provide integrated curative and preventive healthcare to the rural population. Community Health Centers (CHCs) form the uppermost tier and their function is mainly to provide specialized obstetric and child care.

A situational analysis done by the Neonatal Health Research Initiative (NHRI), IndiaClen from 2007-2009, in 24 centers of the country, suggested that less than $20 \%$ of the $\mathrm{CHCs} / \mathrm{PHCs}$ provide essential newborn care services [10]. Also, the availability of a neonatal resuscitation area was relatively low in CHCs (46\%) and PHCs (14\%) [10]. As per the district level health survey (DLHS-3), newborn care equipment was available in only $27.9 \%$ PHCs [11]. Also, while around $76 \%$ of the community health centres had newborn care management facilities, just $35.1 \%$ had facilities for managing low birth weight babies [11]. These findings underscore the critical condition of the public health facilities that are meant to cater to the health problems of the newborns in rural India.

2.2. Status of Trained Healthcare Personnel. Rural public health facilities across the country are having a difficult time attracting, retaining, and ensuring regular presence of highly trained medical personnel especially the gynecologists and pediatricians that are epochal in ensuring and promoting newborn health. Statistics for 2010 suggest a shortfall of $10.3 \%$ for doctors at primary health centers (PHCs) [12]. The condition of 4535 community health centers supposed to provide specialized medical care is even more appalling. As compared to requirements for an existing infrastructure, there was a shortfall of $62.6 \%$ of specialists at the CHCs, $55.2 \%$ of obstetricians and gynecologists and $69.5 \%$ of pediatricians [12]. According to the DLHS-Facility Survey (2003), healthcare facilities with newborn care staff and a medical officer trained in newborn care were 59\%, 45.0\%, and $34 \%$ at district hospital, first referral units (FRUs) and CHCs, respectively [13]. As on March 2010, the overall shortfall in the posts of health worker (female)/auxiliary nurse midwife (ANM) was $8.8 \%$ of the total requirement [12]. Similarly, in case of health worker (male), there was a shortfall of $64.1 \%$ of the requirement. In case of health assistant (female), the shortfall was 31.9\% and that of health assistant (male) was 44\% [12]. The lack of qualified child care specialists results in a majority of rural households receiving care for their ill babies from private providers, many of whom are less than fully qualified.

\section{Key Initiatives to Improve Neonatal Health by the Government of India}

The Government of India has launched various initiatives envisaging a high priority action with regard to neonatal health. Under National Rural Health Mission (NRHM), Accredited Social Health Activists (ASHAs) are being deployed and assigned the responsibility to create awareness in the community regarding maternal and child health issues [14]. They are further expected to mobilize the community and help them in accessing healthcare services. A safe motherhood intervention named "Janani Suraksha Yojana (JSY)" has been implemented under the NRHM to increase the institutional delivery rates and provide skilled care at birth for the newborn [15]. Under the Reproductive and Child Health program (RCH-II), the quality and reach of antenatal care is planned to be expanded and home-based newborn care using integrated management of neonatal and childhood illness (IMNCI) protocols is envisaged.

The IMNCI strategy encompasses a range of interventions to prevent and manage the commonest major childhood and neonatal illnesses that cause death, that is, acute respiratory infections, diarrhoea, measles, malaria, and malnutrition [16]. The IMNCI package is planned to be implemented at the level of household and subcentres (through ANMs) and primary health centres (through medical officers, nurses, and lady health visitors). Till October 2011, it has been implemented in 433 districts across the country [17].

Facility-based care of neonates (F-IMNCI) is proposed through strengthening of infrastructure, provision of extra nurses, and skills upgradation of physicians and nurses [18]. The Government, with the help of UNICEF, has started setting up special care newborn units (SCNUs) for managing sick newborns $[17,19,20]$. These units have been established at district hospitals and are expected to have a minimum of 12 to 16 beds manned by 3 physicians, 10 nurses, and 4 support staff. A total of 293 SNCUs have been established till the year 2011 [17]. Further, Newborn Stabilization Units (NBSUs) are being set up in First Referral Units (FRUs) and Community Health Centers (CHCs) and they aim to provide care to sick newborns referred from peripheral health facilities [17]. As of October 2011, 1134 NBSUs have been set up [17]. A total of 8582 New Born Care Corners (NBCCs), which are special corners within the labour room where resuscitation, infection control, and early breast feeding can be commenced, have been set up, as of 2011 [17].

Janani Shishu Suraksha Karyakram (JSSK) was launched on 1 June, 2011 with the aim to promote institutional delivery, eliminate out-of-pocket expenses, and facilitate prompt referral through free transport [21]. A program 
on basic newborn care and resuscitation, named Navjaat Shishu Suraksha Karyakram (NSSK), is being launched to address important interventions at the time of birth that is, prevention of hypothermia and infections, early initiation of breastfeeding, and basic newborn resuscitation [22]. The objective is to have one person trained in basic newborn care and resuscitation at every delivery. This training is being imparted to medical officers, staff nurses, and ANMs at $\mathrm{CHC}$ /FRUs and $24 \times 7$ PHCs where deliveries are taking place [17]. Provision of Comprehensive Emergency Obstetric and New born Care (CEmONC) Services and Basic Emergency Obstetric and Newborn Care (BEmONC) at various levels has also been given due importance.

Neonatal health is seemingly one of the priority issues in the agenda of the government which gets reflected in the various programs devised and implemented. The worrisome issue is the fact that improving health systems through facility upgradation and ensuring availability of trained manpower and logistics comprise essential prerequisites for the success of these programs/initiatives. The reluctance of trained manpower, especially doctors, to serve in rural areas has become a major impediment in the government's ability to provide quality health services.

\section{Immediate Challenges}

The main obstacles to improving newborn survival are that many babies are born at home without being attended by skilled personnel, faulty home-based newborn care practices are widespread, lack of awareness among care givers limits care-seeking for neonatal illness and even if that is taken care of, lack of trained health workforce adds to the problem. This deficiency in skilled manpower undermines the initiatives by the government to improve neonatal health. Another set of dilemma exists in bringing the neonates and the health system closer to each other. There are broadly two ways of doing so, either bring the health system closer to the neonate or bring the neonate closer to the health system. Both of these are feasible and hold the promise to yield positive results but the real challenge lies in their reproduction and sustainment at the national level.

\section{Way Forward}

5.1. Recruiting and Retaining Doctors in Rural Areas. In order to ensure the availability of trained medical personnel in rural areas, we first need to understand the reasons behind the observed shortage. Recruiting trained doctors by all means is one of the essential components towards providing quality maternal and neonatal care services. A recent report documents that out of the 264 paediatricians (including both postgraduates and diploma holders) that are produced annually in India, only around half of them (i.e., 158) are available for public sector service, a large chunk either emigrate or get attracted towards private sector jobs in urban setups [23]. Similar is the scenario for gynaecologists and obstetricians. The predominant reasons for preference to work in urban areas include adequate infrastructural facilities, high salary, and a decent standard of living [24, 25].

Further, in the recent years, there has been substantial emigration of trained doctors to developed countries, much of it coming from lower and middle income countries [2628]. Among the developing countries, India is the biggest exporter of trained physicians with India-trained physicians accounting for about $10.9 \%$ of British physicians and $4.9 \%$ of American physicians [29]. A report of the National Commission on Macroeconomics and Health documented that around $10 \%$ of the obstetrician(s) and paediatrician(s) that the country produces eventually emigrate [23]. Although the recipient nations and the physicians that emigrate benefit from this migration, the home country loses its important health potentialities.

There is no clear-cut solution to the problem of lack of doctors in rural setup. Interventions in education and financial incentives along with professional support probably have the potential to ease out the problem, as had been seen in rural Australia where the "GPRIP Continuing Medical Education Grants and Locum Grants" designed to assist rural general practitioners to maintain and increase their skills in areas relevant to rural practice helped in their retention in rural areas [30]. The provision of better financial incentives oriented specifically to doctors working in the rural areas might be crucial to attract and retain more doctors in these areas. In Canada, the distribution of doctors was positively influenced by raising fees in rural and underserved areas and reducing fees in "overserved" areas, but in the Philippines, rural incentives had an unintended negative impact due to the fact that local governments were unable to hire healthcare professionals at the high salary levels specified [31-33]. Thus, the experience with paying direct financial incentives, such as rural allowances, has been variable and usually depends on the affordability of resources but this should not undermine the potential it might offer to increase the influx of doctors in rural areas.

Other key initiatives could include establishing rural doctor networks, mentorship programmes, and giving rural practitioners preference in admissions in specialty programs. Exposure to rural areas as part of the training of medical graduates, so they can understand the working conditions and acquire rural clinical skills, is essential and has the potential to yield positive results. This has been documented in Thailand where a majority of graduates continued in rural practice after completing a compulsory rural residency [34]. To prevent brain drain, international scholar exchange programmes could be thought of as an option besides improving healthcare infrastructure and creating an enabling work environment.

\subsection{Promoting Healthy Domiciliary Newborn Care Practices} through Community Mobilization. Poor domiciliary care practices have often been implicated in causing neonatal illness. Several cultural beliefs and traditions that exist in different communities influence care practices. Certain care practices can be deleterious to the health of the baby like applying ghee/oil on cord, early bathing, avoidance of 
colostrum feeding (considering it as harmful for the baby) and not practicing exclusive breast feeding. Realizing the presence of such traditions in the community and formulating intensive information, education, and communication (IEC) campaigns to address these is required.

Further, approaches to improve newborn survival should focus on community mobilization as well. There is a need to develop programs where there is a collective involvement of the communities in order to identify problems and their solutions. Several such programs have been implemented in other parts of the globe and have yielded positive results. One such program was the "Bolivia's Warmi program" where the key highlight was participatory planning at the community level, with an emphasis on women's participation to identify obstetric and perinatal health problems and their potential solutions [38]. As a result of the intervention, neonatal mortality decreased from 120 per 1000 live births to 40 per 1000 live births. In rural Nepal, a cluster randomized trial suggested that women's groups facilitated by a local female community worker could reduce neonatal mortality rates by about 30\% [39]. In eastern India, the Ekjut trial (2005-2008) evaluated the impact of community mobilization on birth outcomes in three districts of Jharkhand and Orissa. The intervention led to a $45 \%$ reduction in neonatal mortality [40]. These studies offer evidence to encourage community involvement and leverage the community resources to bring about improvements in neonatal health. Programs should be designed to acknowledge and maximize these linkages and resources. Further, there is a need to make an effort to integrate community mobilization with health system strengthening.

5.3. Promotion of Home-Based Newborn Care (HBNC). In a review of the evidence-based, cost-effective interventions for reduction of neonatal mortality, Darmstadt et al. documented that a combination of outreach and home-based newborn care at $90 \%$ coverage could avert $18-37 \%$ neonatal deaths [41]. Home-based newborn care could be explicated as a family as well as community oriented services that involve community mobilization and the empowerment of care givers to demand quality services for their sick newborns [42]. HBNC mainly aims at reducing the neonatal deaths by preventing or treating morbidities such as infections, asphyxia or hypothermia which largely form the preventable causes of mortality. Moreover, they are the underlying causes of nearly $55 \%$ of the neonatal deaths in India and addressing them could drastically cut down on the mortality rate [7]. Further, Bhutta et al. have documented that communitybased pneumonia case management can lead to a $27 \%$ decrease in all-cause neonatal mortality, which indeed is a very high achievement [43].

The most convincing example was set out by Bang et al. in rural Gadchiroli where female village health workers were selected from the local population and were trained to identify and manage asphyxiated newborns [44]. They were also trained to manage neonatal sepsis by providing parenteral antibiotic treatment to sick neonates. In the three years of intervention, there was a $71 \%$ reduction in perinatal mortality and a $62 \%$ reduction in neonatal mortality compared with the control area. In another example from Sirur, a periurban area near Pune, Maharashtra, India, forty female village health workers were trained to serve a population of 47,000 . The village worker identified high-risk cases that required treatment by herself and the nurse, under the supervision of the field medical officer. She also made 3 home visits: on day 1 or soon after delivery and on days 8 and 29. As a result of the intervention, a decline in the neonatal mortality rate of $25 \%$ from 51.9 to 38.8 per 1,000 live births was recorded [45]. Other successful examples include trials of home-based care in North India, Bangladesh, Pakistan, and Nepal [46-49].

In addition to creating awareness among community members and care givers in the family through information, education, and communication (IEC) activities, a prerequisite for implementation of home-based care is the development of simple and easily comprehensible standard management guidelines. Further, it would be a challenging task to upscale the home care newborn package to the most vulnerable states such as Uttar Pradesh, Bihar, Jharkhand, Madhya Pradesh, Orissa, and Rajasthan with a high neonatal mortality rate [6].

5.4. Introducing Models of Midwifery Care. In rural India, most of the births (53\%) occur at home largely unattended by skilled personnel [11]. The lack of a trained personnel predisposes the newborn to a variety of birth related complications mainly birth asphyxia, birth injuries, and infections. Moreover, most of the neonatal deaths occur in the first week of life with a majority of them dying on the first day of birth, thus reflecting the poor intrapartum care that the mother receives $[1,50,51]$. With the shortage of trained personnel, nonavailability of adequate healthcare facilities, poor connectivity to a health facility, and lack of transport facilities, providing care at home through training of midwives/traditional birth attendants (TBAs) would probably be a better option. They can be a vital link between women and the health system, giving advice, encouraging women to go to the clinic to deliver, and accompanying mothers to provide moral support.

One such successful case study is from Indonesia [52, 53]. In 2003, nearly half of all newborn deaths in the Cirebon district of Indonesia were due to birth asphyxia. In order to address this situation in Cirebon, Program for Appropriate Technology in Health (PATH) supported by Saving Newborn Lives/Save the Children began for training community midwives (bidan di desas). These midwives were taught a series of initial steps for assessing and managing a newborn's condition, including the use of a locally produced tube and mask resuscitation device that could be used in home birth settings. One year after the training, it was found that newborn deaths due to birth asphyxia dropped by 47 percent in the district, at a cost of only $\$ 42$ per asphyxia death averted [52].

In Zambia, midwife training programs significantly decreased the seven-day neonatal death rate in community health clinics [54]. The midwives were given training in 
essential newborn care (ENC) and in neonatal resuscitation. After training, the all-cause, 7-day neonatal mortality rate decreased from 11.5 deaths per 1000 live births to 6.8 deaths per 1000 live births. The perinatal mortality rate decreased from 18.3 deaths per 1000 births to 12.9 deaths per 1000 births [54]. Similar examples providing evidence for up scaling of trained midwives in order to lower down the neonatal mortality can be drawn from Sri Lanka, Thailand, Malaysia, and Pakistan [55-59].

5.5. Focus on Socioeconomic Development. Infant mortality rates (reflecting neonatal mortality as well) are one of the most important indicators of the differentials in health and socioeconomic condition in a community. A substantial progress in lowering down the high burden of neonatal mortality is unlikely unless ways can be found to enhance the economic wellbeing of the lower socioeconomic groups. A pertinent example is that of Kerala, a southern state of India, where the state's achievement of stabilizing population growth, attaining high levels of literacy, and life expectancy have led to a significant decline in the infant mortality rates $[60,61]$. In a study done in rural Haryana to document the determinants of neonatal deaths, it was found that the occurrence of deaths was a multifactorial process with involvement of factors at community level, family level (socioeconomic), and biological level and that the socioeconomic determinants explained a large proportion of neonatal deaths [62].

Further, Rahman et al. in their study in Qatar found that low-cost, community-based interventions, on the background of socioeconomic development, had a stronger impact on neonatal and perinatal survival as compared to high-cost institutional interventions [63]. Similar findings documenting the importance of socioeconomic development in reducing the burden of neonatal deaths have been reported from studies done in Chile, Malaysia, Malawi, and Arab countries [64-68].

5.6. Capacity Building through Training of Rural Healthcare Practitioners. Neonatal care in rural India is largely provided by a large number of unqualified healthcare providers [6971]. They are the early providers of neonatal care and often attract a large number of ill newborns because of their easier access and comparatively cheaper treatment that they offer. There is a wide range of quality of services provided by these doctors and it would be useful to standardize their services by providing support in the form of training and technical support. Though it does not qualify as a paragon solution, but this concept would probably score well, given the limited resources the country has. In alignment with what had been advocated by Yadav et al. "Let best not be the enemy of the good," it would be beneficial to engage these local healthcare providers and equip them with necessary skills to provide acceptable standards of neonatal care until constraints on the supply of qualified and motivated healthcare providers into the system can be alleviated [72]. They could further be involved in promoting key newborn essential care practices as they are popular and acceptable in the community.
In China, rural healthcare is provided by village doctors who are trained in preventive and curative medicine of both traditional Chinese and allopathic schools. The skills acquired are regularly upgraded by apprenticeship and inservice courses $[73,74]$. Another example is from USA where the shortage of physicians in the 1960s paved the way for the emergence of "physician assistants" who were licensed to practice medicine under the supervision of physicians. They made a considerable contribution by working in rural areas which otherwise would not have received any care at all $[75,76]$. Successful examples of providing quality healthcare through involvement of local healthcare practitioners can also be seen in Ghana, Mexico, and Bangladesh [77, 78].

5.7. Introducing a New Cadre of Healthcare Professional. Providing a degree of "Bachelor of Rural Medicine and Surgery (BRMS)" after three-and-a-half years of training, as opposed to five and-a-half years of training for a usual medical graduate, has recently been discussed as one of the possible options to cater to the need of quality healthcare in rural India [79]. The Government of India, in consultation with the Medical Council of India (MCI), is planning to introduce this course in medical schools proposed to be established at district hospitals. The concept of a new degree course of a comparatively shorter duration is to encourage students from rural areas to take up medicine and subsequently provide services in their respective rural areas. The potential impact of selecting medical students of rural origin has been documented by Rabinowitz et al. in a longitudinal study that evaluated the impact of the Physician Shortage Area Program (PSAP) in the USA [80]. The PSAP combined selective admission criteria with a rurally orientated educational program. On multivariate analysis, rural origin was the single variable most strongly associated with rural practice. Studies done in South Africa, Southern Australia, and Canada have also substantiated that the doctors with rural background have more tendency to work in rural areas [81-83].

Students enrolled in the proposed BRMS course will be taught preclinical as well as clinical subjects with more focus on paediatrics and obstetrics/gynaecology. Further, it is envisaged to impart special training in care of the newborn and vaccination [79]. The BRMS graduates would be allowed to practice only in notified rural areas. Chhattisgarh, a state in central India, has come up with the concept of awarding a degree named "rural medical assistants (RMAs)" [84]. This three-year course was a response to a major crisis in human resources for health that the state faced. Three colleges were inaugurated in 2001 and were situated in rural/tribal districts, but with access to a large government hospital (usually the district hospital) to make it possible for clinical teaching and internship [84]. There has been overwhelming positive response to recruitment of RMAs to the most rural and tribal PHC postings, where previously no trained physician existed.

Establishing a new healthcare cadre would probably have its share of pros and cons. It will certainly improve health care delivery in rural, remote, and tribal areas by 
providing qualified practitioners but the training of these rural healthcare practitioners will be a major area of concern. It is doubtful as to how overworked, poorly staffed, illequipped district hospitals, which cater to thousands of patients, can become quality training grounds for healthcare practitioners. Ensuring that these graduates would practice only in rural areas and not shift to urban setup would be an issue that needs to be addressed. Further, there is a need to document the difference in the quality of care provided by the new cadre of healthcare professional and MBBS graduates.

5.8. Investing in Innovations Such As m-Health. The use of mobile phones to improve the quality of care and enhance efficiency of service delivery within healthcare systems is known as mobile health, or m-Health. WHO defines $\mathrm{m}$ Health as the "provision of health services and information via mobile technologies such as mobile phones and Personal Digital Assistants (PDAs)" [85]. m-Health tools have shown promise in providing greater access to healthcare to populations in developing countries, as well as creating cost efficiencies and improving the capacity of health systems to provide quality healthcare. Studies done in Kenya, Sierra Leone and Zanzibar unleash the immense potentialities this innovative concept holds in addressing a wide variety of healthcare challenges [86-88].

As earlier discussed, in rural setup, access to healthcare professionals and medical facilities is limited. This can lead to situations where treatable medical condition can become life threatening. Although much work has not been done in context of m-Health in India, yet efforts are required to be made to implement this in the Indian context based on the initial success in other developing countries. The feasibility does not seem to be highly questionable considering the recent increase in the number of mobile phone users in rural areas. According to the press release by the Telecom Regularity Authority of India (TRAI), the number of telephone subscribers in India increased to 943.49 million at the end of February 2012 [89]. The share of urban subscribers had been $65.59 \%$ whereas share of rural subscribers had reached $34.41 \%$ [89]. Subscription in rural areas had increased from 320.29 million in January 2012 to 324.68 million in February 2012, an increase of 4.39 million in just one month [89]. Now with the recent initiative by the government to provide a subsidy of 20 percent on bills of less than Rs 300 a month to mobile users in rural India, the increase in the number of mobile users could further be expected [90].

Mobile telephone short-message service (SMS) can be used for delivering health behaviour change interventions. This service has wide population reach, can be individually tailored, and allows instant delivery, suggesting potential as a delivery channel for health behavior interventions. Researchers in Korea, Croatia, New Zealand, and United Kingdom have used SMS to deliver information pertaining to diabetes and asthma self-management, smoking cessation, and increasing physical activity and this has proved to be beneficial by increasing awareness and bringing about the desired behaviour change [91-94]. Mobile technology can also be involved in better training of community health workers in using cellular short messages (SMS) to encode and transmit basic health information such as vital signs and health symptoms to a monitoring computer. Algorithms on the monitoring computer could recognize emergent conditions and send system-generated notification informing the community health worker of the appropriate management of the baby related to the inputted vital signs and symptoms.

5.9. Strengthening Public-Private Partnerships. Given the volume of neonatal care services that are being sought through the private sector in rural areas, one cannot hope to reduce neonatal mortality through public sector interventions alone [69-71]. Because the private sector does not operate within the restrictive confines of a government bureaucracy, one might utilize their services in varied contexts. The advantage with such a partnership could be the wider coverage and increased service utilization. Also, using strengths and skills of each partner enhances efficiency. Successful examples of improving maternal and neonatal health through public private partnerships have been documented in the literature [95-98]. One such example is of Pampers/UNICEF collaboration to eliminate neonatal tetanus [99]. Through this collaboration, over 300 million tetanus vaccines, protecting over 100 million mothers and their babies in 25 of the world's poorest countries, have been provided.

In even the poorest countries, the private sector is a major provider of goods, services, and information for maternal and child health. There could be different ways to involve the private sector, depending on the resources available and the need of services. One of the strategies could be to use microfinance to allow private sector doctors and other healthcare providers to provide quality practices. One such innovative scheme in India is the Chiranjeevi Scheme in Gujarat [98, 100]. It is an innovative health financing scheme covered through public-private partnership for emergency obstetric care and emergency transport services, for women belonging to below poverty line (BPL) category. Private gynecologists are contracted for services that involve conducting normal and complicated deliveries. The financial package is worked out based on 100 deliveries.

Basinga et al. have published an evaluation of a pay for performance (P4P) scheme implemented in Rwanda [101]. P4P scheme involves for-profit organizations who are provided incentives based on improvements in utilization and quality of care. Statistically significant improvements were observed in the maternal and neonatal health $(\mathrm{MNH})$ indicators of institutional delivery and quality of prenatal care which increased by $21 \%$, and $7.6 \%$, respectively over baseline in the P4P districts $[101,102]$.

Introducing public-private partnerships to improve the quality of maternal and child health services is not new in India. Key examples include Vande Mataram Scheme in West Bengal which involves private sector for provision of safe motherhood and family planning services, Janani Express Yojna in Madhya Pradesh for transportation in case of obstetric emergencies, and use of vouchers in Uttar Pradesh where reproductive and child health services for 
below poverty line (BPL) women and children are provided through private practitioners [103, 104]. Under National Rural Health Mission (NRHM), several initiatives based on public-private partnerships have been or/are planned to be implemented. The key issues include sustainability of such initiatives and ensuring that quality services are being provided.

\section{Conclusions}

To conclude, the neonatal mortality rate in India is still high and skewed towards rural areas. Much of the problem lies in the nonavailability of trained manpower and this in turn influences the quality of care the neonates receive. Bringing qualified health professionals to rural, remote, and underserved areas is a challenging task which needs to be addressed urgently to avert neonatal deaths. Other options such as training of local rural healthcare providers and traditional midwives, promoting home-based newborn care, creating community awareness and community mobilization along with strengthening public-private partnerships should be explored further, as evidence generated from previous studies and large scale projects support these strategies as a way to improve neonatal health. More research should be directed towards upcoming innovations such as $\mathrm{m}$-health in order to exploit the potential they offer in terms of enhancing the quality of care.

\section{Key Note}

While the focus should be on devising strategies to recruit and retain trained manpower in rural areas, alternative strategies such as community mobilization, upscaling of home-based newborn care, imparting training and subsequent involvement of local rural healthcare providers and midwives should be attempted as well. More research is required to reveal the potential that innovations such as mhealth, telemedicine, and public-private partnership hold in context to improving the quality of care in rural India.

\section{Authors' Contributions}

R. P. Upadhyay, C. Palanivel, K. Yadav and O. Odukoya conceived the idea and planned the study. R. P. Upadhyay, S. A. Rizwan, S. Sinha, S. Daral and V. G. Chellaiyan and V. Silan did the review of literature. R. P. Upadhyay, P. Chinnakali and O. Odukoya prepared the paper. K. Yadav and P. Chinnakali provided the overall supervision. All the authors read and approved the final paper.

\section{Conflict of Interests}

The authors declare that they have no Conflict of Interests.

\section{References}

[1] J. E. Lawn, S. Cousens, and J. Zupan, "4 Million neonatal deaths: when? Where? Why?” The Lancet, vol. 365, no. 9462, pp. 891-900, 2005.
[2] J. E. Lawn, S. Cousens, Z. A. Bhutta et al., "Why are 4 million newborn babies dying each year?" The Lancet, vol. 364, no. 9432, pp. 399-401, 2004.

[3] National Health Profile Report, Central Bureau of Health Intelligence, Ministry of Health and Family Welfare, pp. 916, 2010, http://cbhidghs.nic.in/writereaddata/mainlinkfile/ file1131.pdf.

[4] Registrar General of India, "Compendium of the vital statistics," in India (1970-2007: Sample Registration System), pp. 1-212, RGI, Ministry of Home Affairs, New Delhi, India, 2009.

[5] http://www.unicef.org/infobycountry/india_statistics.html.

[6] International Institute for Population Sciences, National Family Health Survey (NFHS III), 2005-06, India, vol. 1, International Institute for Population Sciences, Mumbai, India, 2007.

[7] ICMR Young Infant Study Group, "Age profile of neonatal deaths," Indian Pediatrics, vol. 45, no. 12, pp. 991-994, 2008.

[8] A. T. Bang, V. K. Paul, H. M. Reddy, and S. B. Baitule, "Why do neonates die in rural Gadchiroli, India? (Part I): primary causes of death assigned by neonatologist based on prospectively observed records," Journal of Perinatology, vol. 25, supplement 1, pp. S29-S34, 2005.

[9] J. E. Lawn, A. C. Lee, M. Kinney et al., "Two million intrapartum-related stillbirths and neonatal deaths: where, why, and what can be done?" International Journal of Gynaecology and Obstetrics, vol. 107, pp. S5-S19, 2009.

[10] http://www.inclentrust.org/uploadedbyfck/file/complete $\% 20$ Project/22.pdf.

[11] International Institute for Population Sciences (IIPS), District Level Household and Facility Survey (DLHS-3), 2007-08: India, IIPS, Mumbai, India, 2010.

[12] Ministry of Health and Family Welfare, Bulletin on Rural Health Statistics in India, RHS, 2010, http://nrhm-mis .nic.in/Publications.aspx.

[13] International Institute for Population Sciences (IIPS), District Level Household and Facility Survey (DLHS-2), 2003: India, IIPS, Mumbai, India, 2005.

[14] National Rural Health Mission (2005-2012), Mission Document, http://mohfw.nic.in/NRHM/Documents/Mission Document.pdf.

[15] Ministry of Health and Family Welfare, Janani Suraksha Yojana: Guidelines for Implementation, Ministry of Health and Family Welfare, Government of India, 2005, http://www.mohfw.nic.in/NRHM/RCH/guidelines/JSY _guidelines_09_06.pdf.

[16] Ministry of Health and Family Welfare, Student's Handbook for Integrated Management of Neonatal and Childhood Illness, Ministry of Health and Family Welfare, Government of India, World Health Organization, Country Office for India, 2003.

[17] http://www.mohfw.nic.in/NRHM/Documents/Brief _Note_on_CH_Nov_2011.pdf.

[18] Ministry of Health and Family Welfare, Facility Based Newborn Care Operational Guidelines: Guidelines for Planning and Implementation, Ministry of Health and Family Welfare, Government of India, 2011.

[19] "Human resources for facility based newborn care in India: issues and options," http://www.unicef.org/india/ Policy_Brief_HR_SCNU.pdf.

[20] S. B. Neogi, S. Malhotra, S. Zodpey, and P. Mohan, "Assessment of special care newborn units in India," Journal of Health, Population and Nutrition, vol. 29, no. 5, pp. 500-509, 2011. 
[21] Ministry of Health and Family Welfare, Guidelines for Janani Shishu Suraksha Karyakram (JSSK), Maternal HealthDivision, Ministry of Health and Family Welfare, Government of India, http://cghealth.nic.in/ehealth/2011/ jssk/GuidelinesforJSSK1.pdf.

[22] Ministry of Health and Family Welfare, Navjaat Shishu Suraksha Karyakram: Basic Newborn Care and Resuscitation Program Training Manual, Ministry of Health and Family Welfare, Government of India, http://www.nihfw.org/pdf/ NCHRC-Publications/NavjaatShishuTrgMan.pdf.

[23] Report of the National Commission on Macroeconomics and Health, Ministry of Health and Family Welfare, Government of India, 2005, http://www.who.int/macrohealth/action /Report\%20of\%20the\%20National\%20Commission.pdf,.

[24] S. Murthy, K. Rao, S. Ramani, M. Chokshi, N. Khandpur, and I. Hazarika, "What do doctors want? Incentives to increase rural recruitment and retention in India," BMC Proceedings, vol. 6, supplement 1, P5, 2012.

[25] S. Raha, P. Berman, I. Saran, T. Verma, A. Bhatnagar, S. Awasthi et al., "Career preferences of medical and nursing students in Uttar Pradesh: a qualitative analysis," HRH Technical Report 3, 2012, http://www.hrhindia.org/assets/images/ Paper-III.pdf.

[26] M. Kaushik, A. Jaiswal, N. Shah, and A. Mahal, "High-end physician migration from India," Bulletin of the World Health Organization, vol. 86, no. 1, pp. 40-45, 2008.

[27] S. Dodani and R. E. LaPorte, "Brain drain from developing countries: how can brain drain be converted into wisdom gain?" Journal of the Royal Society of Medicine, vol. 98, no. 11, pp. 487-491, 2005.

[28] S. E. Brotherton, P. H. Rockey, and S. I. Etzel, "US graduate medical education, 2003-2004," The Journal of the American Medical Association, vol. 292, no. 9, pp. 1032-1037, 2004.

[29] F. Mullan, "The metrics of the physician brain drain," The New England Journal of Medicine, vol. 353, no. 17, pp. 18101818, 2005.

[30] J. S. Humphreys and F. Rolley, "A modified framework for rural general practice: the importance of recruitment and retention," Social Science and Medicine, vol. 46, no. 8, pp. 939-945, 1998.

[31] M. Fournier, "Les politiques de main-d'oeuvre médicale au Québec: bilan 1970-2000," Ruptures (Revue Transdisciplinaire en Santé), vol. 7, pp. 79-98, 2001.

[32] S. Wibulpolprasert, "Inequitable distribution of doctors: can it be solved?" Human Resources Development Journal, vol. 3, pp. 2-22, 1999.

[33] N. W. Wilson, I. D. Couper, E. de Vries, S. Reid, T. Fish, and B. J. Marais, "A critical review of interventions to redress the inequitable distribution of healthcare professionals to rural and remote areas," Rural and Remote Health, vol. 9, no. 2, article 1060, 2009.

[34] S. Wibulpolprasert and P. Pengpaibon, "Integrated strategies to tackle the inequitable distribution of doctors in Thailand: for decades of experience," Human Resources for Health, vol. 1, article 12, 2003.

[35] A. J. Kesterton and J. Cleland, "Neonatal care in rural Karnataka: healthy and harmful practices, the potential for change," BMC Pregnancy and Childbirth, vol. 9, article 20, 2009.

[36] M. Bandyopadhyay, "Impact of ritual pollution on lactation and breastfeeding practices in rural West Bengal, India," International Breastfeeding Journal, vol. 4, article 2, 2009.
[37] R. P. Upadhyay, B. Singh, S. K. Rai, and K. Anand, "Role of cultural beliefs in influencing selected newborn care practices in rural Haryana," Journal of Tropical Pediatrics, vol. 58, no. 5, pp. 406-408, 2012.

[38] L. Howard-Grabman, G. Seoane, C. Davenport, and MotherCare and Save the Children, The Warmi Project: A Participatory Approach to Improve Maternal and Neonatal Health: An Implementor's Manual, John Snow International, Mothercare Project, Save the Children, Westport, Conn, USA, 2002.

[39] P. D. S. Manandhar, D. Osrin, B. P. Shrestha et al., "Effect of a participatory intervention with women's groups on birth outcomes in Nepal: cluster-randomised controlled trial," The Lancet, vol. 364, no. 9438, pp. 970-979, 2004.

[40] P. Tripathy, N. Nair, S. Barnett et al., "Effect of a participatory intervention with women's groups on birth outcomes and maternal depression in Jharkhand and Orissa, India: a cluster-randomised controlled trial," The Lancet, vol. 375, no. 9721, pp. 1182-1192, 2010.

[41] G. L. Darmstadt, Z. A. Bhutta, S. Cousens, T. Adam, N. Walker, and L. de Bernis, "Evidence-based, cost-effective interventions: how many newborn babies can we save?" The Lancet, vol. 365, no. 9463, pp. 977-988, 2005.

[42] A. K. Dutta, "Home-based newborn care: how effective and feasible?" Indian Pediatrics, vol. 46, no. 10, pp. 835-840, 2009.

[43] Z. A. Bhutta, A. K. M. Zaidi, D. Thaver, Q. Humayun, S. Ali, and G. L. Darmstadt, "Management of newborn infections in primary care settings: a review of the evidence and implications for policy?" Pediatric Infectious Disease Journal, vol. 28, no. 1, pp. S22-S30, 2009.

[44] A. T. Bang, R. A. Bang, S. B. Baitule, M. H. Reddy, and M. D. Deshmukh, "Effect of home-based neonatal care and management of sepsis on neonatal mortality: field trial in rural India," The Lancet, vol. 354, no. 9194, pp. 1955-1961, 1999.

[45] A. Pratinidhi, U. Shah, A. Shrotri, and N. Bodhani, "Riskapproach strategy in neonatal care," Bulletin of the World Health Organization, vol. 64, no. 2, pp. 291-297, 1986.

[46] V. Kumar, S. Mohanty, A. Kumar et al., "Effect of community-based behaviour change management on neonatal mortality in Shivgarh, Uttar Pradesh, India: a clusterrandomised controlled trial," The Lancet, vol. 372, no. 9644, pp. 1151-1162, 2008.

[47] A. H. Baqui, S. El-Arifeen, G. L. Darmstadt et al., "Effect of community-based newborn-care intervention package implemented through two service-delivery strategies in Sylhet district, Bangladesh: a cluster-randomised controlled trial," The Lancet, vol. 371, no. 9628, pp. 1936-1944, 2008.

[48] Z. A. Bhutta, Z. A. Memon, S. Soofi, M. S. Salat, S. Cousens, and J. Martines, "Implementing community-based perinatal care: results from a pilot study in rural Pakistan," Bulletin of the World Health Organization, vol. 86, no. 6, pp. 452-459, 2008.

[49] P. D. S. Manandhar, D. Osrin, B. P. Shrestha et al., "Effect of a participatory intervention with women's groupson birth outcomes in Nepal: cluster-randomised controlled trial," The Lancet, vol. 364, no. 9438, pp. 970-979, 2004.

[50] H. Gelband, J. Liljestrand, L. Nemer, M. Islam, J. Zupan, and P. Jha, "The evidence base for interventions to reduce maternal and neonatal mortality in low and middle income countries. Commission on Macroeconomics and Health (CMH) Working Paper Series," WG5 Paper 
5, 2012, http://library.cphs.chula.ac.th/Ebooks/HealthCareFinancing/WG5/Paper\%20no.WG5_5.pdf.

[51] J. E. Lawn, K. Kerber, C. Enweronu-Laryea, and O. M. Bateman, "Newborn survival in low resource settings-are we delivering?" BJOG: An International Journal of Obstetrics and Gynaecology, vol. 116, no. 1, pp. 49-59, 2009.

[52] Program for Appropriate Technology in Health (PATH), Reducing Birth Asphyxia Through the Bidan di Desa Program in Cirebon, Indonesia: Final Report, PATH, Jakarta, Indonesia.

[53] I. Ariawan, Reducing Birth Asphyxia Through the Bidan di Desa Program in Cirebon, Indonesia:, PATH, Jakarta, Indonesia, 2006.

[54] W. A. Carlo, E. M. McClure, E. Chomba et al., "Newborn care training of midwives and neonatal and perinatal mortality rates in a developing country," Pediatrics, vol. 126, no. 5, pp. e1064-e1071, 2010.

[55] V. K. Paul and M. Singh, "Regionalized perinatal care in developing countires," Seminars in Neonatology, vol. 9, no. 3, pp. 117-124, 2004.

[56] D. G. H. de Silva, "Perinatal care in Sri Lanka: secrets of success in a low income country," Seminars in Neonatology, vol. 4, no. 3, pp. 201-207, 1999.

[57] I. Pathmanathan and J. Liljestrand, Investing in Maternal Health: Learning from Malaysia and Sri Lanka, World Bank, Washington, DC, USA, 2003.

[58] L. de Bernis, D. R. Sherratt, C. AbouZahr, and W. van Lerberghe, "Skilled attendants for pregnancy, childbirth and postnatal care," British Medical Bulletin, vol. 67, pp. 39-57, 2003.

[59] A. H. Jokhio, H. R. Winter, and K. K. Cheng, "An intervention involving traditional birth attendants and perinatal and maternal mortality in Pakistan," The New England Journal of Medicine, vol. 352, no. 20, pp. 2091-2099, 2005.

[60] K. C. Zachariah and S. I. Rajan, Eds., Kerala's Demographic Transition-Determinants and Consequences, Sage, New Delhi, 1997.

[61] G. Parayil, "The "Kerala model" of development: development and sustainability in the third World," Third World Quarterly, vol. 17, no. 5, pp. 941-957, 1996.

[62] R. P. Upadhyay, P. R. Dwivedi, S. K. Rai, P. Misra, M. Kalaivani, and A. Krishnan, "Determinants of neonatal mortality in rural Haryana: a retrospective population based study," Indian Pediatrics, vol. 49, no. 4, pp. 291-294, 2012.

[63] S. Rahman, K. Salameh, A. Bener, and W. E. Ansari, "Socioeconomic associations of improved maternal, neonatal, and perinatal survival in Qatar," International Journal of Women's Health, vol. 2, no. 1, pp. 311-318, 2010.

[64] L. N. Kazembe and P. M. Mpeketula, "Quantifying spatial disparities in neonatal mortality using a structured additive regression model," PloS ONE, vol. 5, no. 6, Article ID e11180, 2010.

[65] R. Gonzalez, M. Merialdi, O. Lincetto et al., "Reduction in neonatal mortality in Chile between 1990 and 2000," Pediatrics, vol. 117, no. 5, pp. e949-e954, 2006.

[66] J. Davanzo, "Infant mortality and socioeconomic development: evidence from Malaysian household data," Demography, vol. 25, no. 4, pp. 581-595, 1988.

[67] T. N. Peng, T. B. Ann, and H. Arshat, "Multivariate areal analyses of neo-natal mortality in peninsular Malaysia," Malaysian Journal of Reproductive Health, vol. 3, no. 1, pp. 46-58, 1985.

[68] M. Abuqamar, D. Coomans, and F. Louckx, "Correlation between socioeconomic differences and infant mortality in the Arab World (1990-2009)," International Journal of Sociology and Anthropology, vol. 3, no. 1, pp. 15-21, 2011.
[69] J. R. Willis, V. Kumar, S. Mohanty et al., "Gender differences in perception and care-seeking for illness of newborns in rural Uttar Pradesh, India," Journal of Health, Population and Nutrition, vol. 27, no. 1, pp. 62-71, 2009.

[70] P. Mohan, S. D. Iyengar, K. Agarwal, J. C. Martines, and K. Sen, "Care-seeking practices in rural Rajasthan: barriers and facilitating factors," Journal of Perinatology, vol. 28, supplement 2, pp. S31-S37, 2008.

[71] M. Kaushal, R. Aggarwal, A. Singal, H. Shukla, S. K. Kapoor, and V. K. Paul, "Breastfeeding practices and health-seeking behavior for neonatal sickness in a rural community," Journal of Tropical Pediatrics, vol. 51, no. 6, pp. 366-376, 2005.

[72] K. Yadav, P. Jarhyan, V. Gupta, and C. Pandav, "Revitalizing rural health care delivery: can rural health practitioners be the answer?" Indian Journal of Community Medicine, vol. 34, no. 1, pp. 3-5, 2009.

[73] D. Zhang and P. U. Unschuld, "China's barefoot doctor: past, present, and future," The Lancet, vol. 372, no. 9653, pp. 18651867, 2008.

[74] R. Ballweg, S. Stolberg, and E. M. Sullivan, Eds., Physician: A Guide to Clinical Practice, WB Saunders, Philadelphia, Pa, USA, 2nd edition, 1999.

[75] D. E. Mittman, J. F. Cawley, and W. H. Fenn, "Physician assistants in the United States," British Medical Journal, vol. 325, no. 7362, pp. 485-487, 2002.

[76] A. Kamalakanthan and S. Jackson, "A qualitative analysis of the retention and recruitment of rural general practitioners in Australia," http://espace.uq.edu.au/eserv/UQ:158901/ econ_374_0908.pdf.

[77] W. Hoff, "Traditional health practitioners as primary health care workers," Tropical Doctor, vol. 27, supplement 1, pp. 52$55,1997$.

[78] Traditional practitioners as primary health care workers, $A$ Study of Effectiveness of Four Training Projects in Ghana, Mex$i c o$ and Bangladesh, Division of Strengthening of Health Services and Traditional Medicine Programme, Geneva, Switzerland, 1995, http://archives.who.int/tbs/trm/h2941e.pdf.

[79] S. Garg, R. Singh, and M. Grover, "Bachelor of rural health care: do we need another cadre of health practitioners for rural areas?" National Medical Journal of India, vol. 24, no. 1, pp. 35-37, 2011.

[80] H. K. Rabinowitz, J. J. Diamond, M. Hojat, and C. E. Hazelwood, "Demographic, educational and economic factors related to recruitment and retention of physicians in rural Pennsylvania," Journal of Rural Health, vol. 15, no. 2, pp. 212-218, 1999.

[81] E. de Vries and S. Reid, "Do South African medical students of rural origin return to rural practice?" South African Medical Journal, vol. 93, no. 10, pp. 789-793, 2003.

[82] D. Wilkinson, J. J. Beilby, D. J. Thompson, G. A. Laven, N. L. Chamberlain, and C. O. M. Laurence, "Associations between rural background and where South Australian general practitioners work," Medical Journal of Australia, vol. 173, no. 3, pp. 137-140, 2000.

[83] M. Easterbrook, M. Godwin, R. Wilson et al., "Rural background and clinical rural rotations during medical training: effect on practice location," Canadian Medical Association Journal, vol. 160, no. 8, pp. 1159-1163, 1999.

[84] T. Sundararaman, S. Raha, G. Gupta, K. Jain, K. R. Antony, and K. Rao, "Chhattisgarh experience with 3-year course for rural health care practitioners: a case study," http://cghealth.nic.in/ehealth/studyreports/chhattisgarh $\% 20$ experience $\% 20$ with $\% 203$-year.pdf. 
[85] http://www.who.int/kms/en/.

[86] R. T. Lester, P. Ritvo, E. J. Mills et al., "Effects of a mobile phone short message service on antiretroviral treatment adherence in Kenya (WelTel Kenya1): a randomised trial," The Lancet, vol. 376, no. 9755, pp. 1838-1845, 2010.

[87] mHealth for maternal and newborn health in resourcepoor and health system settings, Sierra Leone, 2011, http://www.dfid.gov.uk/r4d/PDF/Outputs/Misc/technicalbrief-mhealth-SierraLeone.pdf.

[88] S. Lund, "Use of mobile phones to improve maternal and neonatal health in Zanzibar," http://www.enrecahealth.dk/ archive/wiredmothers.

[89] http://www.trai.gov.in/WriteReadData/PressRealease/Document/InfoPress-Telecom\%20Subscription\%20Data_\% 2029022012.pdf.

[90] http://www.thehindubusinessline.com/industry-andeconomy/info-tech/article2796120.ece?homepage=true \&ref=wl_home.

[91] H. S. Kwon, J. H. Cho, H. S. Kim et al., "Development of web-based diabetic patient management system using short message service (SMS)," Diabetes Research and Clinical Practice, vol. 66, supplement, pp. S133-S137, 2004.

[92] V. Ostojic, B. Cvoriscec, S. B. Ostojic, D. Reznikoff, A. StipicMarkovic, and Z. Tudjman, "Improving asthma control through telemedicine: a study of short-message service," Telemedicine Journal and e-Health, vol. 11, no. 1, pp. 28-35, 2005.

[93] A. Rodgers, T. Corbett, D. Bramley et al., "Do u smoke after txt? Results of a randomised trial of smoking cessation using mobile phone text messaging," Tobacco Control, vol. 14, no. 4, pp. 255-261, 2005.

[94] R. Hurling, M. Catt, M. de Boni et al., "Using internet and mobile phone technology to deliver an automated physical activity program: randomized controlled trial," Journal of Medical Internet Research, vol. 9, no. 2, article e7, 2007.

[95] S. Sharma and V. Dayaratna, "Creating conditions for greater private sector participation in achieving contraceptive security," Health Policy, vol. 71, no. 3, pp. 347-357, 2005.

[96] M. Huff-Rousselle and H. Pickering, "Crossing the publicprivate sector divide with reproductive health in Cambodia: out-patient services in a local NGO and the national $\mathrm{MCH}$ clinic," International Journal of Health Planning and Management, vol. 16, no. 1, pp. 33-46, 2001.

[97] J. O. Schmidt, T. Ensor, A. Hossain, and S. Khan, "Vouchers as demand side financing instruments for health care: a review of the Bangladesh maternal voucher scheme," Health Policy, vol. 96, no. 2, pp. 98-107, 2010.

[98] R. Bhat, D. V. Mavalankar, P. V. Singh, and N. Singh, "Maternal healthcare financing: Gujarat's Chiranjeevi scheme and its beneficiaries," Journal of Health, Population and Nutrition, vol. 27, no. 2, pp. 249-258, 2009.

[99] http://www.unicef.org/infobycountry/drcongo_60501.html.

[100] A. Singh, D. V. Mavalankar, R. Bhat et al., "Providing skilled birth attendants and emergency obstetric care to the poor through partnership with private sector obstetricians in Gujarat, India," Bulletin of the World Health Organization, vol. 87, no. 12, pp. 960-964, 2009.

[101] P. Basinga, P. J. Gertler, A. Binagawho, A. L. B. Soucat, J. R. Sturdy, and C. M. J. Vermeersch, "Paying primary health care centers for performance in Rwanda," Policy Research Working Paper Series WPS5190, The World Bank Human Development Network Chief Economist's Office and Africa Region Health, Nutrition and Population Unit, 2010.
[102] S. Madhavan, D. Bishai, C. Stanton, and A. Harding, "Engaging the private sector in maternal and neonatal health in low and middle income countries," Future Health Systems Innovations for Equity, Working Paper 12, 2010, http://futurehealthsys.squarespace.com/storage/publications/working-papers/wp13.pdf.

[103] A. K. Sharma, "National rural health mission: time to take stock," Indian Journal of Community Medicine, vol. 34, no. 3, pp. 175-182, 2009.

[104] IFPS Technical Assistance Project (ITAP), Sambhav: Vouchers Make High-Quality Reproductive Health Services Possible for India's Poor, Futures Group, ITAP, Gurgaon, India, 2012, http://www.usaid.gov/in/newsroom/ pdfs/svs_rpt.pdf. 


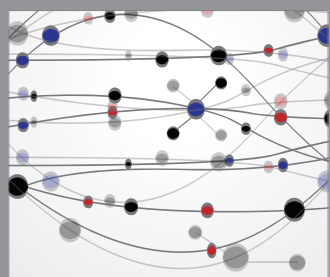

The Scientific World Journal
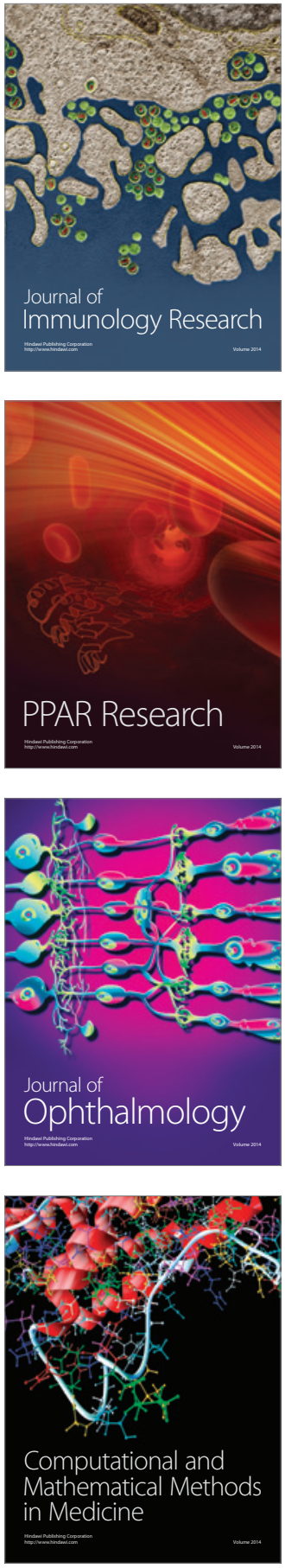

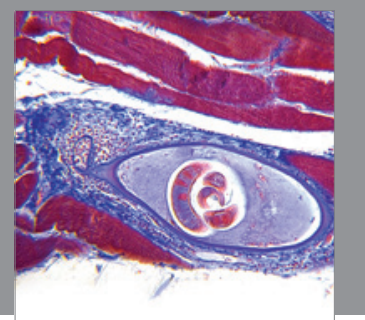

Gastroenterology

Research and Practice
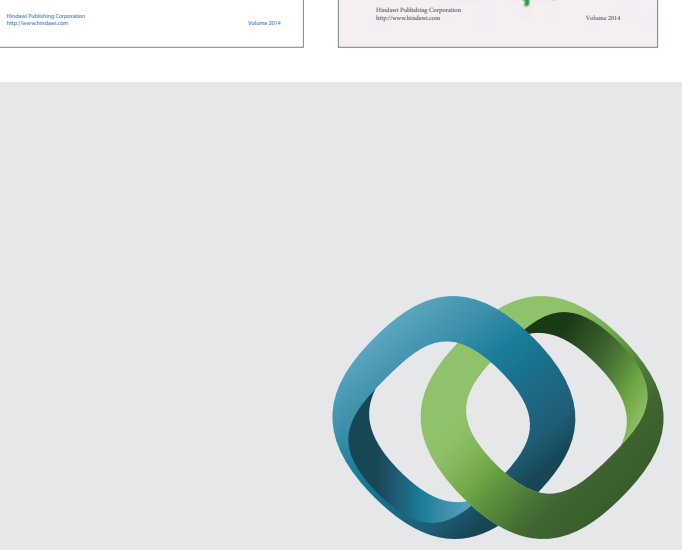

\section{Hindawi}

Submit your manuscripts at

http://www.hindawi.com
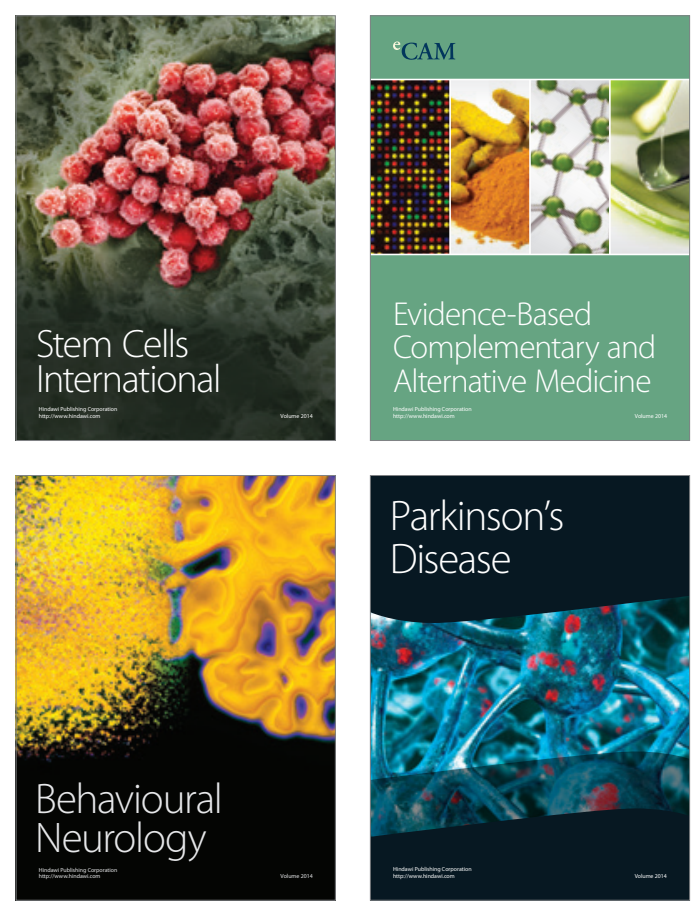

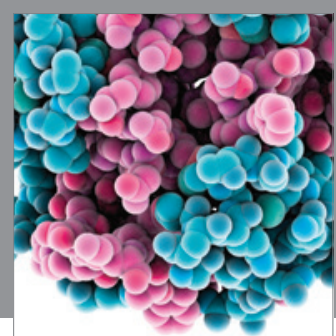

Journal of
Diabetes Research

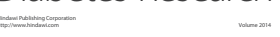

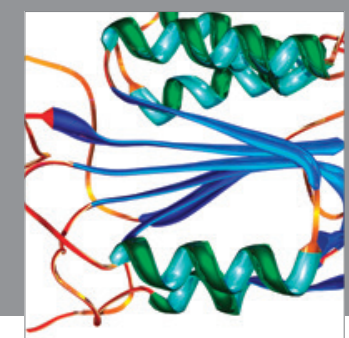

Disease Markers
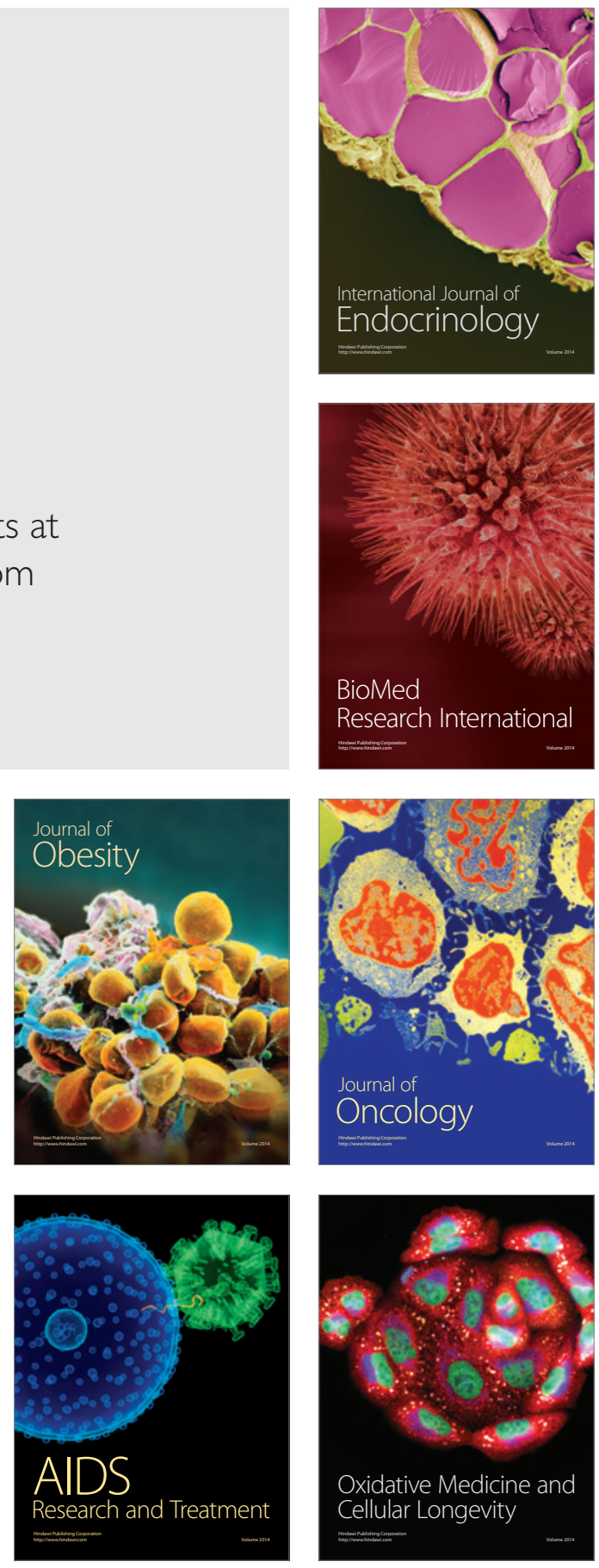